\title{
Magma Ascension Rates in Auckland Volcanic Field Revealed by Elemental Diffusion in Olivine Xenocrysts
}

\author{
VICTORIA CASSADY1, MADISON ANAE1, INGRID \\ UKSTINS 1, MARCO BRENNA2, SHANE CRONIN3, IAN \\ SMITH3
}

1EES Department, Univ. of Iowa, Iowa City, IA 52242, USA

${ }_{2}$ Department of Geology, Univ. of Otago, Dunedin, NZ

3School of Environment, Univ. of Auckland, Auckland, NZ

(victoria-cassady@uiowa.edu, madison-anae@uiowa.edu,

ingrid-peate@uiowa.edu, marco.brenna@otago.ac.nz,

s.cronin@auckland.ac.nz, ie.smith@auckland.ac.nz)

Auckland is the largest city in New Zealand, with 1.5 million residents, and is built on top of the Auckland Volcanic Field, which contains more than 53 individual volcanoes supplied by a single magma source. These volcanoes range in age from 300,000 to 600 years old, and are monogenetic basaltic maar and scoria cones, which means they erupt over a short period of time (weeks to months). Recent work on chemical diffusion profiles from mantle sourced olivine xenocrysts from the oldest eruption shows that there may be as little as a few days to a few hours of warning before the next eruption takes pace. A significant subset of these diffusion profiles also suggest multi-stage magma storage not explained by the conventional model of magma ascension in monogenetic basalts, which assumes rapid, continuous magma ascension. This project focuses on the younger volcanoes from this field and uses greyscale analysis of BSE images of diffusion gradients in $>1000$ olivines derived from Pupuke maar (AVF). Local Fe and $\mathrm{Mg}$ concentration is derived by high resolution electron microprobe analysis (ca. $2 \mu \mathrm{m}$ spacing) and is associated with a greyscale color scheme via ImageJ using the same methodology described in Brenna et al. 2018, resulting in a statistically quantifiable elemental diffusion profile for each olivine. These diffusion profiles in olivine are an optimal tool to calculate the amount of time the crystal spent equilibrating in the mantle before magma ascension and how rapidly eruption occurred. This will provide insight into potential warning times for future eruptions and will reveal complexities of the magma storage systems in the lithospheric mantle below the Auckland volcanic field, which is poorly understood. This information is critical to inform on public hazard planning and response for Auckland and other urban areas located on or near monogenetic volcanic fields, significantly improving public safety. 